\title{
Investigation on Dissolution Pattern and Mathematical Modeling of Drug Release of UDCA by Complextaion with $\beta$-Cyclodextrin-Choline Dichloride Coprecipitate
}

\author{
Kamal Dua ${ }^{1, *}$ and Kavita Pabreja ${ }^{2}$
}

${ }^{1}$ Department of Pharmaceutical Technology, School of Pharmacy and Health Sciences, International Medical University, Bukit Jalil, Kuala Lumpur, Malaysia-57000

${ }^{2}$ Department of Life Sciences, School of Pharmacy and Health Sciences, International Medical University, Bukit Jalil, Kuala Lumpur, Malaysia-57000

\begin{abstract}
The objective of the present investigation was to study the effect of presence of choline dichloride (CDC) in $\beta$-cyclodextrin $(\beta-C D)$ on in vitro dissolution of Ursodeoxycholic acid (UDCA) from molecular inclusion complexes. The molecular inclusion complexes of UDCA with $\beta-C D$ coprecipitated with CDC were prepared using kneading method. In vitro dissolution of pure drug, physical mixtures and cyclodextrin inclusion complexes (UDCA- $\beta$-CDCDC) were carried out. Molecular inclusion complexes of Ursodeoxycholic acid with coprecipitated $\beta-C D$ showed considerable increase in the dissolution rate in comparison with physical mixture and pure drug in $0.1 \mathrm{~N} \mathrm{HCl}, \mathrm{pH} 1.2$ and phosphate buffer, $\mathrm{pH}$ 7.4. Inclusion complexes with 1:2M ratio showed maximum dissolution rate in comparison to other ratios. FT-IR spectroscopy and differential scanning calorimetry studies indicated no interaction between UDCA and $\beta-C D-C D C$ in complexes in solid state. Dissolution enhancement was attributed to the formation of water soluble inclusion complexes with the precipitated form of $\beta-C D$. The in vitro release from all the formulations was best described by first order kinetics followed by Higuchi release model. In conclusion, dissolution of Ursodeoxycholic acid can be enhanced by using the $\beta-C D-C D C$ coprecipitate as a host molecule.
\end{abstract}

Keywords: Ursodeoxycholic acid; $\beta-C D ; C D C$;solubility;complexes

\section{Introduction}

Up to 40 percent of new chemical entities discovered by the pharmaceutical industry today are poorly soluble or lipophilic compounds [1]. The solubility issues complicating the delivery of these new drugs also affect the delivery of many existing drugs. Poorly watersoluble drugs show unpredictable absorption, since their bioavailability depends upon dissolution in the gastrointestinal tract [2-4]. The dissolution characteristics of poorly soluble drugs can be enhanced by several methods [5-7]. Cyclodextrin and their derivatives play an important role in formulation development due to their effect on solubility, dissolution rate, chemical stability and absorption of drugs. Though cyclodextrins have been investigated widely during the last two decades, their commercial application in pharmaceutical formulation was started only in recent years with drugs such as piroxicam and nimesulide [8].

Ursodeoxycholic acid (UDCA) (Figure 1) is a white, odorless, crystalline powder with a bitter taste. Chemically it is $3 \alpha, 7 \beta$-dihydroxy5 -cholan-24-oic acid. It is a water insoluble drug used as a drug for the dissolution of cholesterol gallstones because it reduces the cholesterol saturation of bile [9-11]. The use of UDCA for the treatment of other liver diseases, such as primary biliary cirrhosis, chronic hepatitis and biliary pains has been demonstrated [12-14]. However in vivo studies have shown that intestinal absorption and consequently the bioavailability of the drug are generally poor and erratic both among different subjects, and within the same subject. More than 50\% is lost in the stool after a single oral dose of $300 \mathrm{mg}$.

The possibility to increase the complexing ability of $\beta-\mathrm{CD}$ by their prior coprecipitation with molecules like choline dichloride able to increase the aqueous solubility of lipophilic drugs seemed to represent a further approach to the utilization of $\beta-\mathrm{CD}$ as aqueous solubility and therefore attempt has been made to prepare inclusion complexes of Ursodeoxycholic acid with coprecipitated $\beta$-cyclodextrin $(\beta-C D)$ with an aim to improve its extent and rate of dissolution.

\section{Material and Methods}

Ursodeoxycholic acid (Lab. Chem. Sdn. Bhd., Malaysia), $\beta$-cyclodextrin ( $\beta$-CD) (Himedia Laboratories Limited, Mumbai) of commercial purity grade were used. All other chemicals used were of analytical reagent grade.

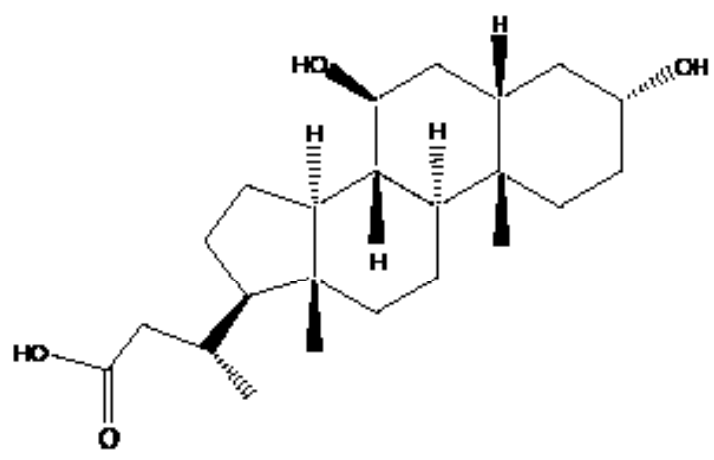

Figure 1: Ursodeoxycholic acid

*Corresponding author: Kamal Dua, Lecturer, Department of Pharmaceutical Technology, Faculty of Medicine \& Health Sciences, International Medica University, Bukit Jalil, 57000 KL, Malaysia, E-mail: kamalpharmacist@gmail.com kamal_dua@imu.edu.my

Received September 22, 2011; Accepted December 07, 2011; Published December 10, 2011

Citation: Dua K, Pabreja K (2011) Investigation on Dissolution Pattern and Mathematical Modeling of Drug Release of UDCA by Complextaion with b-Cyclodextrin-Choline Dichloride Coprecipitate. J Liver 1:101. doi:10.4172/2167 0889.1000101

Copyright: () 2011 Dua K, et al. This is an open-access article distributed unde the terms of the Creative Commons Attribution License, which permits unrestricted use, distribution, and reproduction in any medium, provided the original author and source are credited. 


\section{Preparation of $\beta$-CD- Choline Dichloride ( $\beta$-CD-CDC) Coprecipitate}

$\beta$-CD (10 g; $8.81 \mathrm{mmol})$ was dissolved in $100 \mathrm{ml}$ of DMSO. CDC ( $1.4 \mathrm{~g} ; 8.81 \mathrm{mmol}$ ) was added. The solution was stirred for $24 \mathrm{~h}$ at $50^{\circ}$ C. After this period a di-ethyl ether-acetone $(2: 1 \mathrm{v} / \mathrm{v})$ mixture was added to the solution to induce coprecipitation of $\beta$-CD and CDC. The precipitate obtained was subsequently washed first with the diethyl ether-acetone mixture and subsequently with diethyl ether and dried under vaccum [15]

\section{Preparation of Physical Mixtures}

The physical mixtures were prepared by manually mixing pre weighed amounts of mesh. No 100 -sieve fractions of UDCA, $\beta$-CD and CDC [16]. The mixing was performed adopting the geometric dilution method.

\section{Preparation of Molecular Inclusion Complexes}

Solid inclusion complexes of UDCA with $\beta$-CD-CDC were prepared in 1:1 and 1:2 molar ratios using kneading method. Accurately weighed quantity of $\beta$-CD-CDC was taken in a glass mortar; water was added slowly and mixed to obtain a homogeneous paste. Weighed quantity of UDCA was added slowly by grinding. The mixture was ground for one hour. During this process appropriate quantity of water was added to maintain suitable consistency. The obtained solid mass was further dried under vaccum to a constant weight at room temperature and pulverized, sieved through mesh \# 100 and stored in dessicator $[15,16]$.

\section{Phase Solubility Studies}

The phase solubility studies were performed according to the method reported by Higuchi and Connors [17,22]. Excess amount of UDCA (50 mg) was added to $25 \mathrm{ml}$ of aqueous solution ( $\mathrm{pH} \mathrm{7.0)}$ containing various concentrations of $\beta-\mathrm{CD}(1-15 \mathrm{mM})$ in a series of stoppered conical flask and the mixtures were shaken at $30^{\circ} \mathrm{C}$ for 24 $\mathrm{h}$ at room temperature on a rotary flask shaker. After equilibration, the solutions were filtered immediately using $0.5 \mu$ nylon disk filter. The filtered samples were suitably diluted and assayed for drug content using HPLC method [18]. Shaking of aqueous solutions of drugs and $\beta$-CD were continued until the three consecutive estimations were same. The apparent stability constant $\left(\mathrm{K}_{\mathrm{c}}\right)$, according to the hypothesis of $1: 1$ stoichiometric ratio of the complexes was calculated from the straight line of the phase solubility diagram by using equation 1 .

$$
\mathrm{K}_{\mathrm{c}}=\frac{\text { Slope }}{\text { Intercept }(1-\text { Slope })}
$$

The values of $\mathrm{K}_{\mathrm{c}}$ indicated the stability of the drug- $\beta$-CD complexes. The solubility experiments were conducted in triplicate.

\section{Characterisation of Molecular Inclusion Complexes}

Percent yield: The percent yield of molecular inclusion complexes was calculated on the basis of dry weight (drug and carriers) and the final weight of molecular inclusion complexes was obtained [19].

$$
\text { Percent yield }=\frac{\text { Dry weight of the product }}{\text { Dry weight of the drug and polymers }} \times 10
$$

Average particle size: The molecular inclusion complexes were dispersed in liquid paraffin and mounted on slides. Particle size of 200 particles was measured using calibrated stage micrometer and ocular micrometer. From the data the average particle size was calculated [19].
Hygroscopic studies: The molecular inclusion complexes were dried in a dessicator under anhydrous calcium chloride for two days. One hundred mg each of molecular inclusion complexes $\left(\mathrm{w}_{1}\right)$ was placed on a watch glass and exposed to ambient atmospheric conditions $\left(70 \pm 5 \% \mathrm{RH}, 30 \pm 2^{\circ} \mathrm{C}\right)$ and saturation humidity conditions $(99 \pm 1 \% \mathrm{RH}$, $30 \pm 2^{\circ} \mathrm{C}$ ) for 2 days. The substance was weighed again $\left(\mathrm{w}_{2}\right)$. The gain in the weight was determined and the percentage moisture gained was calculated, using the below given equation [20].

$$
\text { Percent moisture absorbed }=\frac{\left(w_{2}-w_{1}\right)}{w_{1}} \times 100
$$

Drug content: Content of UDCA in molecular inclusion complexes was estimated using HPLC method.

\section{Scanning electron microscopy}

Scanning Electron Microscopy (SEM) was carried out for 1:1 molecular inclusion complexes. The surface morphology of the selected binary systems was studied using a Phillips 1500, scanning electron microscope (JSM-840, JEOL, Japan). The powders were previously fixed on a brass stub using double sided adhesive tape and then were made electrically conductive by coating in vaccum, with a thin layer of gold (approximately $300 \AA$ ), for 30 s and at $30 \mathrm{~W}$. The micrographs were taken at an excitation voltage of $15 \mathrm{KV}$ and a magnification of 750 or $5000 \mathrm{X}$ [20].

\section{Fourier transformed infrared spectroscopic studies}

Fourier transformed infrared (FTIR) spectra were routinely obtained to assess the drug-carrier interaction using Shimadzu FTIR8400S Fourier transform infrared spectrophotometer. FTIR spectral studies were carried out for pure drug, freshly prepared and six months old 1:1 molecular inclusion complexes and individual substances to check the compatibility between drug and carriers. Interaction between the components, if any, was indicated by either producing additional peaks or absence of the characteristic peaks corresponding to the drug and carrier $[21,26]$

\section{Differential scanning calorimetric studies}

Differential scanning calorimetric (DSC) studies were carried to check the compatibility between drug and carriers. DSC studies were carried out for pure drug, freshly prepared and six months old 1:1 molecular inclusion complexes. All dynamic DSC studies were carried out on a calibrated Shimadzu DSC-50 Thermal Analyzer. Calorimetric measurements were made with empty cell (high purity alpha alumina discs as reference). The dynamic scans were taken in nitrogen atmosphere at the heating rate of $10^{\circ} \mathrm{C} /$ minute. Interaction between the drug and polymer, if any, was indicated either by a shift in the peak or presence of additional peaks at temperatures other than those corresponding to the drug and carrier $[21,23]$.

\section{$\mathrm{X}$-Ray diffractometry}

The physical state of pure drug, freshly prepared and six months old 1:1 molecular inclusion complexes. was evaluated by $\mathrm{X}$-ray diffraction $(\mathrm{X}-\mathrm{RD})$. Powder $\mathrm{X}-\mathrm{RD}$ was carried out with the Philips X-ray diffractometer (PW 1050/PW 1710) using Ni-filtered, $\mathrm{CuK}_{\alpha}$ radiation $(\mathrm{I}=1.5418 \AA$ ), a voltage of $40 \mathrm{kV}$ and a current of $40 \mathrm{~mA}$. The scanning rate was $6^{\circ} / \mathrm{min}$ over a $2 \theta$ range of $5-50^{\circ}$, chart speed $10 \mathrm{~mm} /$ min and count range $1000 \mathrm{cps}[23,24,26]$.

\section{In vitro release studies}

In vitro release studies were carried out using basket type USP XXII 
Citation: Dua K, Pabreja K (2011) Investigation on Dissolution Pattern and Mathematical Modeling of Drug Release of UDCA by Complextaion with b-Cyclodextrin-Choline Dichloride Coprecipitate. J Liver 1:101. doi:10.4172/2167-0889.1000101

dissolution test apparatus [18]. Release studies were carried separately for pure drug, physical mixtures and molecular inclusion complexes of UDCA $2 \mathrm{~h}$. Pure drug (100 mg) and formulations containing drug content equivalent to $100 \mathrm{mg}$ of UDCA was separately studied for in vitro release. Dissolution was carried out in $900 \mathrm{ml}$ of $0.1 \mathrm{~N}$ hydrochloric acid solution, $\mathrm{pH} 1.2$ and phosphate buffer, $\mathrm{pH} 7.4$ separately, with a stirring speed of $50 \mathrm{rpm}$ at a temperature of $37 \pm 0.5^{\circ} \mathrm{C}$. Five $\mathrm{ml}$ aliquots of dissolution medium were withdrawn at an interval of 5 minutes for first 15 minutes and then 15 minutes intervals, for rest of the two-hour study and filtered through a $0.45 \mu$ filter. The volume withdrawn at each time was replaced with an equal volume of pre-warmed dissolution medium. The drug content was estimated using the HPLC method. The dissolution experiments were conducted in triplicate [24,25].

\section{Kinetic analysis of drug release}

The dissolution profiles of all the molecular inclusion complexes were subjected to the kinetic analysis to establish the drug-release mechanism. The release data were fitted to zero order (Equation 4), first order (Equation 5), matrix (Higuchi model) (Equation 6) and HixsonCrowell equations (Equation 7) to ascertain the kinetic modeling of drug release [24].

$$
\begin{aligned}
& Q_{t}=k_{0} t \\
& \ln Q_{t}=\ln Q_{0}-k_{1} t \\
& Q_{t}=k_{H} t^{1 / 2} \\
& Q_{0}^{1 / 3}-Q t^{1 / 3}=k_{H C} t
\end{aligned}
$$

Where $Q_{t}$ is the amount of drug released at time $t, Q_{0}$ is the initial amount of drug in the formulation and $k_{0}, k_{1}, k_{H} \& k_{H C}$ are release rate constants for zero-order, first-order, Higuchi model and HixsonCrowell rate equation [27-29].

\section{Result and Discussion}

\section{Phase solubility studies}

Phase solubility studies of UDCA--CD systems in water at $25^{\circ} \mathrm{C}$ revealed that the solubility of UDCA increased linearly with the increase in the concentration of $\beta-C D$, showing a typical $A_{L}$-type phase solubility curve. Since the slope of the phase solubility curve was $<1$ for UDCA, the increase in solubility was due to the formation of stoichiometric $1: 1 \mathrm{M}$ complex in solution with $\beta$-CD. The apparent stability constant $\left(\mathrm{K}_{c}\right)$ was calculated from the slope of the linear plot of the phase solubility diagram and was found to be $479.14 \mathrm{M}^{-1}$.

\section{Characterisation of molecular inclusion complexes of usrodeoxycholic acid}

All the UDCA - $\beta$-CD-CDC molecular inclusion complexes prepared were found to be fine and free flowing powders.

Percent yield: As indicated in Table 1 the percentage yield ranged from 85.2 to $88.3 \%$ for the $\beta$-CD molecular inclusion complexes. Low coefficient of variance $(\mathrm{CV})$ values $(<1.0 \%)$ in percentage yield indicates the reproducibility of the technique employed for the preparation of molecular inclusion complexes.

Average particle size: Average particle size was found to be within the range of $56.2 \mu \mathrm{m}$ to $77.5 \mu \mathrm{m}$ (Table 1 ). This narrow range of particle size was satisfactory from the point of improving the aqueous solubility.

Drug content: The percentage entrapment of the drug in molecular inclusion complexes was found to be approximately nearer to the theoretical values (Table 1). Low value for CV $(<1.0)$ indicates uniformity of drug content in the product. The obtained results implied that the drug remained stable during preparation.

Hygroscopic Studies: Results for the percent weight gain by $\beta-C D$ complexes are shown in Table 2 . The hygroscopicity of binary system containing UDCA $-\beta$-CD-CDC in $1: 2 \mathrm{M}$ ratio was found to be more

\begin{tabular}{|c|c|c|l|l|l|l|}
\hline Product & Drug : carrier & Percent yield & $\begin{array}{c}\text { Particle size range } \\
(\boldsymbol{\mu m})\end{array}$ & $\begin{array}{c}\text { Average particle size } \\
(\boldsymbol{\mu m})\end{array}$ & $\begin{array}{c}\text { Drug content } \\
(\mathbf{m g})\end{array}$ & \begin{tabular}{c} 
Percent drug content \\
\hline UDCA- $\boldsymbol{\beta} C D-C D C 1$
\end{tabular} \\
\hline $\mathbf{1 : 1 M}$ & $\begin{array}{c}\mathbf{8 5 . 2} \\
\mathbf{( 0 . 7 9 )}\end{array}$ & $5.3-137.5$ & $56.2(0.45)$ & $31.5(33)^{*}$ & $95.4(0.82)$ \\
\hline UDCA- $\boldsymbol{\beta} C D-C D C 2$ & $\mathbf{1 : 2 M}$ & $88.3(0.84)$ & $6.2-134.3$ & $77.5(0.18)$ & $48.1(50)^{*}$ & $96.0(0.89)$ \\
\hline
\end{tabular}

UDCA: Ursodeoxycholic acid; CDC: choline dichloride; $\beta-C D$ : $\beta$-cyclodextrin; M: molar. Values in parenthesis indicates the standard deviation ( $\mathrm{n}=3$ ) and values given in the parenthesis marked with * indicates theoretical values of drug content.

Table 1: Physical characteristics of molecular inclusion complexes of Ursodeoxycholic acid.
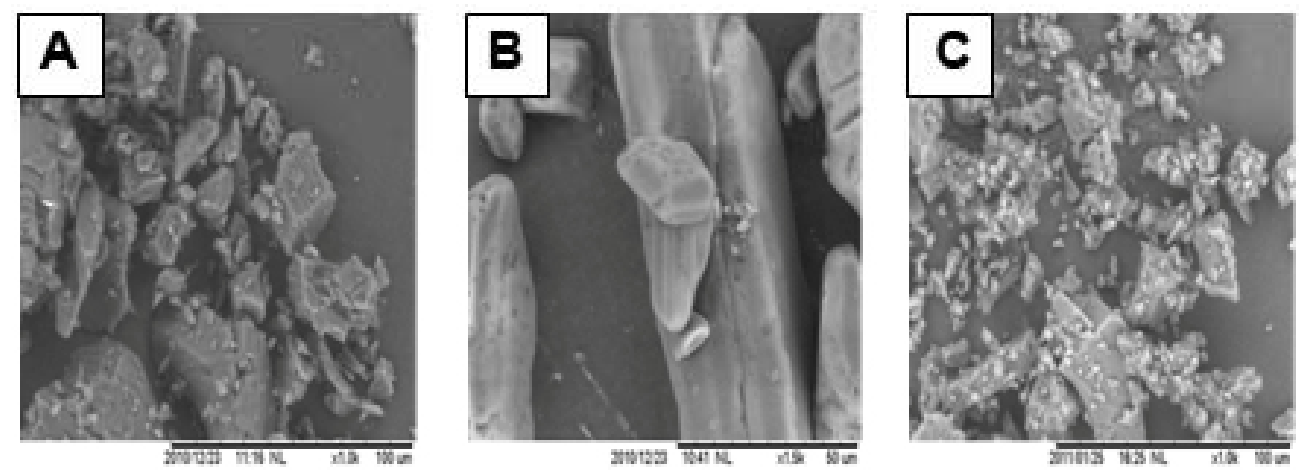

Figure 2: Scanning electron photomicrographs of ursodeoxycholic acid (A); $\beta$-cyclodextrin (B); UDCA- $\beta$-CD-CDC inclusion complex (1:2 M) (C). 
Citation: Dua K, Pabreja K (2011) Investigation on Dissolution Pattern and Mathematical Modeling of Drug Release of UDCA by Complextaion with b-Cyclodextrin-Choline Dichloride Coprecipitate. J Liver 1:101. doi:10.4172/2167-0889.1000101

in comparison with other carriers under ambient as well as saturation humidity conditions. Similar results were reported by Sethia and Squilante [30] with carbamazepine and Martinez-ohariz et al. [31] with diflunisal.

Scanning electron microscopy: The scanning electron micrographs of UDCA molecular inclusion complexes of UDCA are given in Figure 2. UDCA appeared as irregular shaped crystals and $\beta-C D$ has shown a parallelogram shape. The original morphology of all other binary systems (molecular inclusion complexes) had disappeared and it was not possible to differentiate between the two components. All the binary systems appeared as agglomerates exhibiting the presence of a homogeneous solid phase of amorphous nature. Existence of a single phase is also responsible for the enhanced drug dissolution in comparison to pure UDCA.

Fourier transformed infrared spectroscopic studies: All the characteristic bands of UDCA were observed in the molecular inclusion complexes. Broadening of bands was observed to a large extent. The characteristic bands of $\beta$-CD $\left(3305,1420,1460\right.$ and $\left.1083 \mathrm{~cm}^{-1}\right)$ were
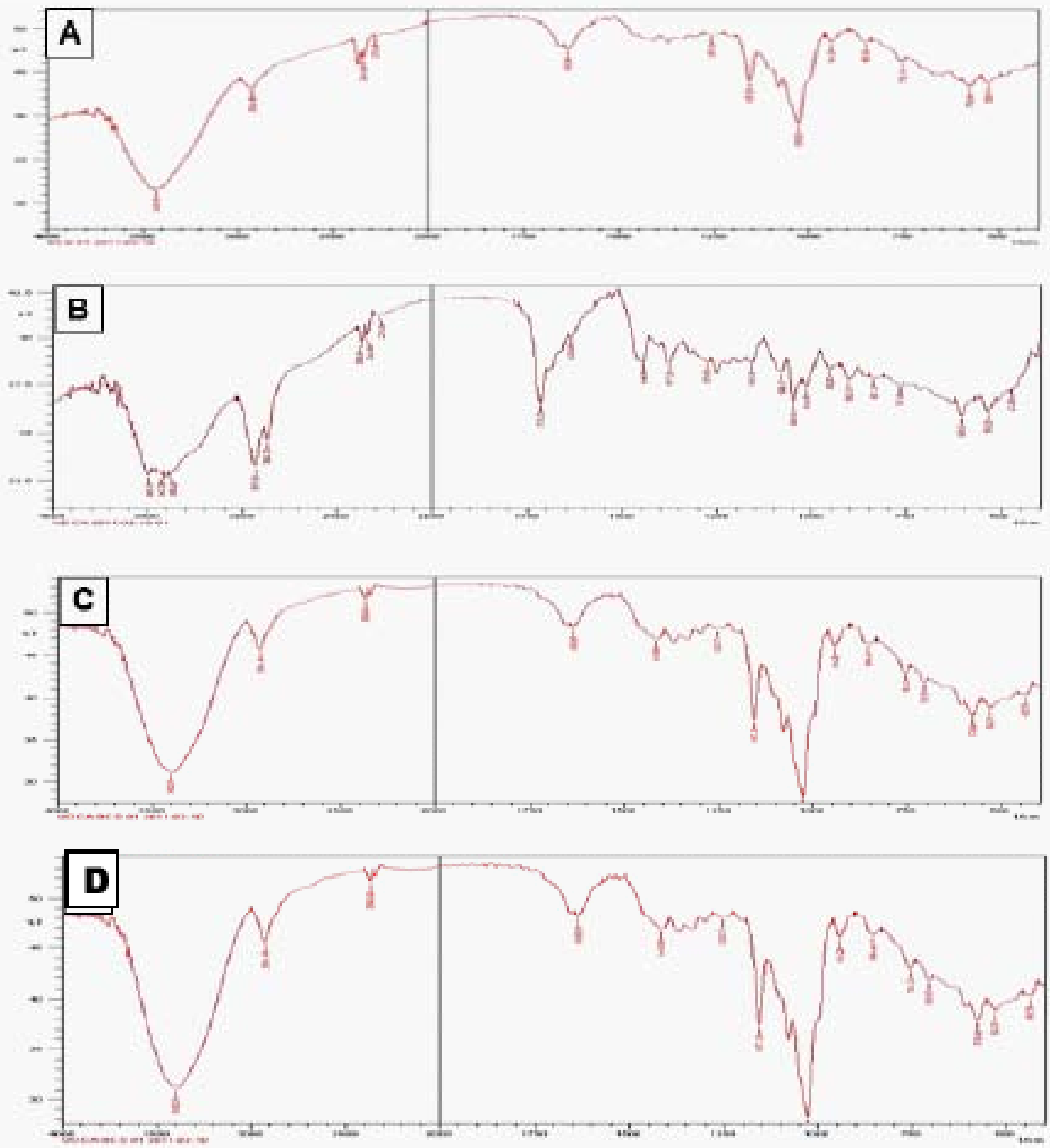

Figure 3: FTIR spectra of ursodeoxycholic acid and different $\beta$-cyclodextrin-CDC complexes. (A) UDCA; (B) $\beta C D$; (C) UDCA- $\beta C D-C D C$ (complex) 1:1 M; (D) UDCA$\beta C D-C D C$ (complex) 1:2M. UDCA= ursodeoxycholic acid; $\beta C D=\beta$-cyclodextrin; $C D C=$ choline dichloride; $M=$ molar. 

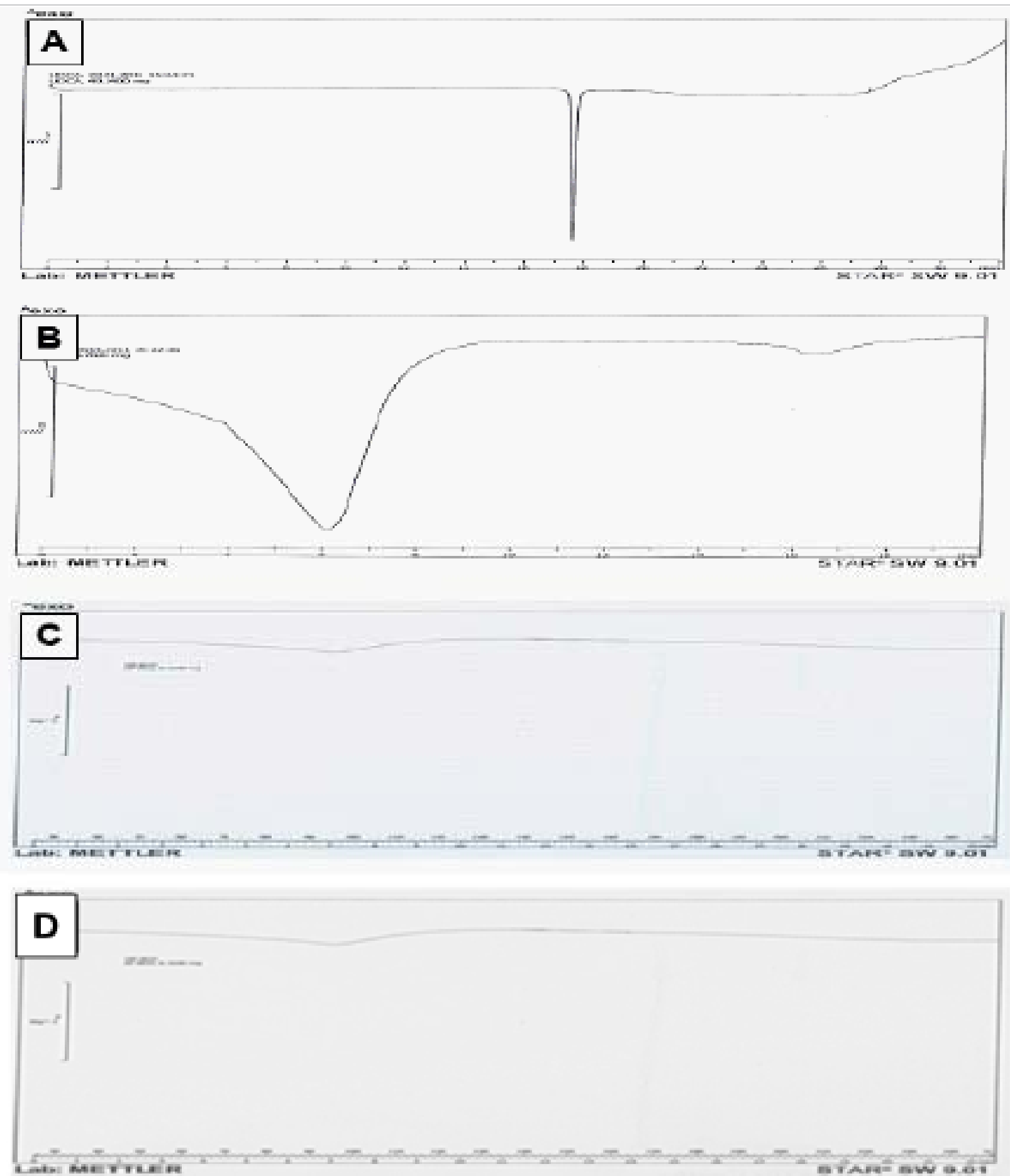

Figure 4: DSC thermogram of (A) UDCA; (B) $\beta-C D$; (C) UDCA- $\beta-C D-C D C$ 1:1M (complex); (D) UDCA- $\beta-C D-C D C$ 1:2M (complex). UDCA= ursodeoxycholic acid; $\beta-C D=\beta$-cyclodextrin; $C D C=$ choline dichloride; $M=$ molar

also observed (Figure 3). The FTIR spectra of physical mixtures and complexes indicate reduction in the intensity of several peaks like $\mathrm{O}-\mathrm{H}$ (s) and $\mathrm{C}-\mathrm{H}(\mathrm{s})$. The absence of any significant change in the IR spectral pattern in the formulations containing the drug and carriers indicated the absence of interaction between the drug and carriers employed for the solubility enhancement.
Differential scanning calorimetric studies: The differential scanning calorimetric (DSC) thermograms of UDCA, $\beta-C D, C D C$, physical mixtures and $\beta$-cyclodextrin-CDC complexes are given in Figure 3 . The pure UDCA exhibited endothermic peak at $203^{\circ} \mathrm{C}$ which represents the melting of UDCA and in accordance with the literature value [27]. $\beta-C D$ and $\mathrm{CDC}$ showed endothermic peaks at $104^{\circ} \mathrm{C}$ and $230^{\circ} \mathrm{C}$ respectively. $\beta$-CD peak at $104{ }^{\circ} \mathrm{C}$ may be attributed to the dehydration process. 
Citation: Dua K, Pabreja K (2011) Investigation on Dissolution Pattern and Mathematical Modeling of Drug Release of UDCA by Complextaion with b-Cyclodextrin-Choline Dichloride Coprecipitate. J Liver 1:101. doi:10.4172/2167-0889.1000101

Page 6 of 9

The DSC curve of UDCA - $\beta$-CD-CDC physical mixtures show peaks resulting from the superposition of their separated component DSC curves. In contrast, disappearance of endothermic peak corresponding to UDCA was observed in the DSC curves of UDCA - $\beta$-CD-CDC complexes. The disappearance of this peak may be probably due to the interaction of UDCA with $\beta$-CD-CDC and formation of inclusion complexes (Figure 4). DSC thermograms indicate the existence of the new solid phase and confirm FTIR spectral data concerning the presence of UDCA in an amorphous and homogenously dispersed state in $\beta$-CD-CDC. The DSC further supported that UDCA was compatible
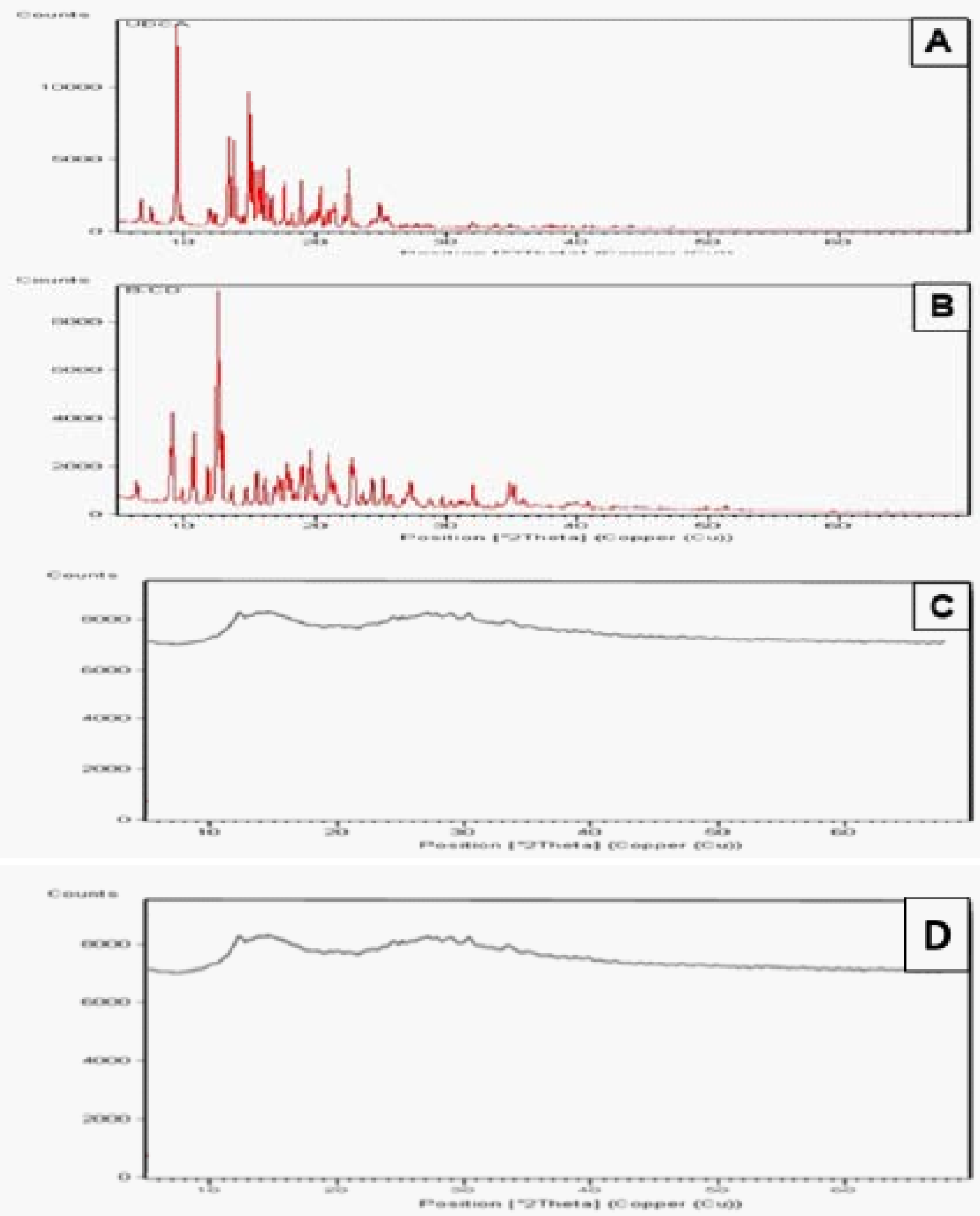

Figure 5: XRPD diffractogram of (A) UDCA; (B) $\beta-C D$; (C) UDCA- $\beta-C D-C D C$ 1:1M (complex); (D) UDCA- $\beta-C D-C D C$ 1:2M (complex). UDCA= ursodeoxycholic acid; $\beta$-CD $=\beta$-cyclodextrin; $C D C=$ choline dichloride; $M=$ molar. 


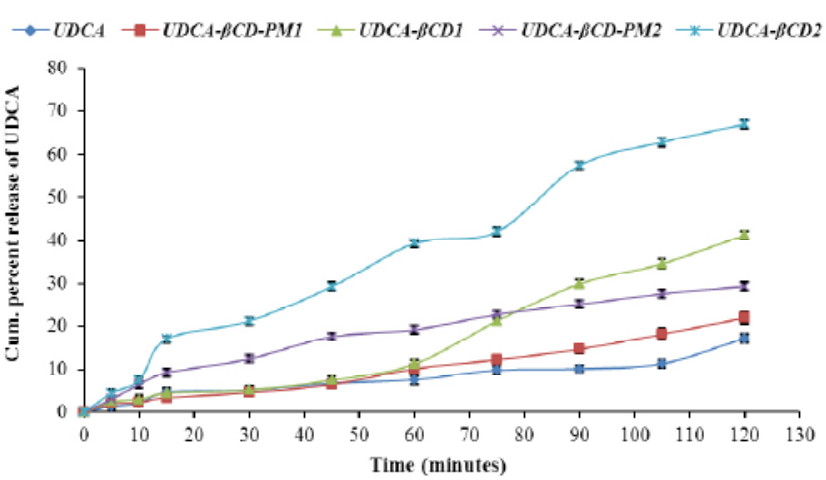

Figure 6: In vitro dissolution profile of ursodeoxycholic acid- $\beta-C D-C D C$ inclusion complexes and their physical mixtures in $0.1 \mathrm{~N} \mathrm{HCl}, \mathrm{pH} 1.2$.

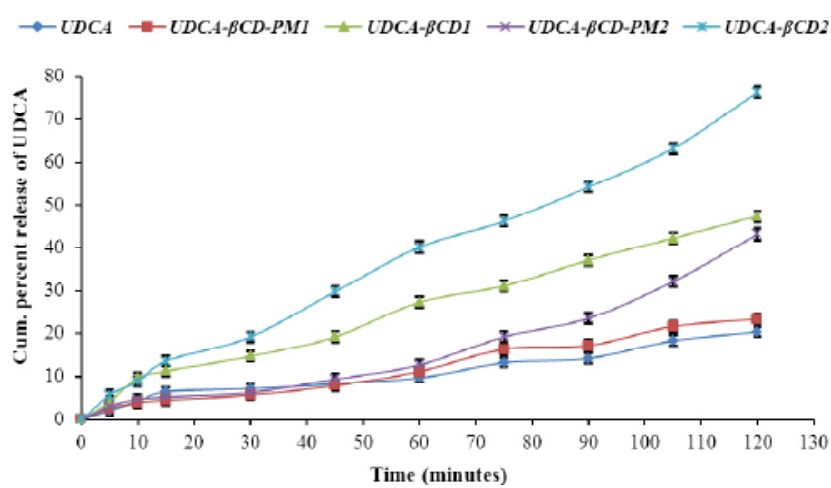

Figure 7: In vitro dissolution profile of ursodeoxycholic acid- $\beta-C D-C D C$ inclusion complexes and their physical mixtures in phosphate buffer, $\mathrm{pH} 7.4$.

with $\beta$-CD-CDC system. No additional or shift in endothermic peaks were observed which indicated the compatibility between the drug and carriers. The findings indicated that the drug was stable in $\beta$-CD-CDC molecular inclusion complexes prepared freshly and after 6 months storage.

$\mathrm{X}$-Ray diffractometry: X-ray diffractometry $(\mathrm{X}-\mathrm{RD})$ pattern of UDCA, $\beta$-CD, CDC, physical mixtures and $\beta$-cyclodextrin-CDC complexes are given in Figure 5.The X-RD pattern of pure UDCA showed sharp and characteristic high intensity diffraction peaks at $2 \theta$ values of $9.76,12.23,16.12,20.51,22.57$ and 24.72 . The numerous diffraction peaks with high intensities in ursodeoxycholic acid its existence in a highly crystalline state, while in $\beta$-cyclodextrin-CDC complexes, X-RD patterns showed a broad diffraction band with markedly reduced intensity.The results indicate the existence of UDCA in amorphous state and hence showing enhanced aqueous solubility. The obtained results are in confirmation with the microscopic studies.

In vitro release studies: In both, $0.1 \mathrm{~N} \mathrm{HCl}(\mathrm{pH} 1.2)$ and phosphate buffer ( $\mathrm{pH}$ 7.4), the physical mixtures and molecular inclusion complexes with all UDCA: $\beta$-CD-CDC ratios exhibited faster dissolution rates than that of pure UDCA at all time points. The dissolution rate of $\beta$-CD-CDC molecular inclusion complexes was faster as compared to their corresponding physical mixtures at all the time intervals (Table 3 , Figure 6,7). With the increase in the proportion of $\beta$-CD-CDC, rate of dissolution of molecular inclusion complexes increased.

All the UDCA complexes showed a better dissolution profile in phosphate buffer, $\mathrm{pH} 7.4$ in comparison to $0.1 \mathrm{~N} \mathrm{HCl}, \mathrm{pH}$ 1.2. The drug release from different formulations were ranked as $\beta$-CD-CDC molecular inclusion complex $>$ physical mixtures $>$ pure drug (UDCA).

It was also found that 1:2 $\mathrm{M}$ ratio of UDCA- $\beta C D-C D C$ showed maximum dissolution both in $0.1 \mathrm{~N} \mathrm{HCl}, \mathrm{pH} 1.2(64.1 \pm 0.95 \%)$ and phosphate buffer, $\mathrm{pH} 7.4(72.3 \pm 1.30 \%)$. The increase in dissolution rate is due to the formation of water soluble inclusion complexes with the $\beta$-CD-CDC. The water molecules in the cavities of $\beta$-CD-CDC are in an energetically unfavored state because of the apolar nature of the cavity. Replacement of high energy water molecules with a hydrophobic guest in cavity is therefore favored. The removal of high energy molecule out of the cavity by displacement is the driving force for the formation of an inclusion complex in aqueous solution. The guest molecule is associated with $\beta$-CD-CDC by non-covalent and weak intermolecular forces.

The interactions between the hydrophobic part of the guest and the apolar cavity causes dehydration of the hydrophobic guest molecule and its transfer into the cavity, thereby increasing the affinity towards water and hence increasing the dissolution [32]. The surfactant like properties of CDs can also be postulated to explain the higher dissolution rate of

\begin{tabular}{|c|c|c|c|c|c|c|}
\hline \multirow{2}{*}{ Formulation code } & \multirow{2}{*}{ Drug: Carrier } & \multirow{2}{*}{$\begin{array}{l}\text { Initial weight } \\
\quad \text { (mg) }\end{array}$} & \multicolumn{2}{|c|}{$\begin{array}{l}\text { Ambient conditions } \\
(70 \pm 5 \% \mathrm{RH}, 30 \pm 2 \mathrm{C})\end{array}$} & \multicolumn{2}{|c|}{$\begin{array}{l}\text { Saturation humidity conditions } \\
(99 \pm 2 \% \mathrm{RH}, 30 \pm 2 \mathrm{C})\end{array}$} \\
\hline & & & Final weight (mg) & $\begin{array}{c}\text { Percent weight gained } \\
\text { (mg) }\end{array}$ & $\begin{array}{l}\text { Final weight } \\
\text { (mg) }\end{array}$ & $\begin{array}{c}\text { Percent weight gained } \\
(\mathrm{mg})\end{array}$ \\
\hline UDCA & Pure drug & 100 & 100.3 & $0.3(0.17)$ & 101.6 & $1.6(0.13)$ \\
\hline UDCA- $\beta C D-C D C 1$ & $1: 1 \mathrm{M}$ & 100 & 101.3 & $1.3(0.15)$ & 103.7 & $3.7(0.14)$ \\
\hline UDCA-ßCD-CDC2 & $1: 2 M$ & 100 & 101.5 & $1.5(0.13)$ & 107.2 & $7.2(0.26)$ \\
\hline
\end{tabular}

UDCA: Ursodeoxycholic acid; CDC: choline dichloride; $\beta$-CD: $\beta$-cyclodextrin; M: molar. Values in parenthesis indicates the standard deviation ( $n=3$ )

Table 2: Determination of hygroscopicity of molecular inclusion complexes of ursodeoxycholic acid.

\begin{tabular}{|c|c|c|c|}
\hline \multirow{2}{*}{ Composition } & \multirow{2}{*}{ Ratio } & \multicolumn{2}{|c|}{ Percent drug released after $2 \mathrm{hr}$} \\
\hline & & $0.1 \mathrm{~N} \mathrm{HCl}, \mathrm{pH} 1.2$ & Phosphate buffer, pH 7.4 \\
\hline UDCA (Pure Drug) & 1:0 & $17.2(0.91)$ & $20.3(1.02)$ \\
\hline UDCA- $\beta C D-C D C 1$ (PM) & $1: 1$ & $21.9(1.15)$ & $23.3(1.32)$ \\
\hline UDCA- $\beta C D-C D C 2$ (PM) & $1: 2$ & $29.3(0.95)$ & $43.2(1.49)$ \\
\hline UDCA- $\beta C D-C D C 1$ & $1: 1$ & $41.2(1.07)$ & $47.4(0.31)$ \\
\hline UDCA- $\beta C D-C D C 2$ & $1: 2$ & $67.1(0.92)$ & $76.3(1.21)$ \\
\hline
\end{tabular}

UDCA: ursodeoxycholic acid; $\beta$-CD: $\beta$-cyclodextrin; CDC: choline dichloride; M: molar; PM: physical mixture. Mean and standard deviation (in parenthesis), $\mathrm{n}=6$

Table 3: In vitro dissolution profile of ursodeoxycholic acid $\beta C D--C D C$ molecular inclusion complexes in $0.1 \mathrm{~N} \mathrm{HCl}, \mathrm{pH} 1.2$ and phosphate buffer, pH 7.4 
Citation: Dua K, Pabreja K (2011) Investigation on Dissolution Pattern and Mathematical Modeling of Drug Release of UDCA by Complextaion with b-Cyclodextrin-Choline Dichloride Coprecipitate. J Liver 1:101. doi:10.4172/2167-0889.1000101

the complexes [32]. CDs can also reduce the interfacial tension between the solid particles of drug and the dissolution medium, leading to a greater rate of dissolution [33]. Increased solubility of physical mixture over the pure drug can be attributed to the wetting of hydrophobic surface of UDCA due to solubilisation of water-soluble carrier.

Kinetic analysis of drug release: The kinetics of in vitro release of the best formulations of UDCA (UDCA- $\beta C D-C D C 1: 2 \mathrm{M}$ ) was carried out. The release of drug from all formulations was observed to follow the first order release kinetics, since the correlation coefficient $\left(\mathrm{R}^{2}\right)$ for first order was higher in comparison to zero order release. The results were in agreement with the previous investigations performed by Shivkumar et al. [34]. A higher correlation, as indicated by $\mathrm{R}^{2}$ was observed for the Higuchi matrix release kinetics in all the selected formulations suggesting the diffusion as a probable prominent mechanism of drug release [35,36]. In diffusion, the rate of dissolution of drug particles within the matrix must be much faster than that of the diffusion rate of drug leaving the matrix.

\section{Conclusion}

The present study clearly shows that addition of $\beta$-CD-CDC coprecipitate to Ursodeoxycholic acid improves its dissolution rate. Further, all the molecular inclusion complexes performed better than the corresponding physical mixtures. FT-IR spectroscopy and differential scanning calorimetry studies indicated no interaction between usrodeoxycholic acid and $\beta$-CD-CDC in complexes in solid state. The above studies conclude that complexation of UDCA with $\beta$-CD lends an ample credence in enhancing its dissolution profile, which in turn have potential to produce a faster onset of action and will also be helpful in dose reduction.

\section{References}

1. Hite M, Turner S, Federici C (2003) Part 1. Oral Delivery of Poorly Soluble Drugs, Pharmaceutical Manufacturing and Packing Sourcer, Summer

2. Goldberg AH, Gibaldi M, Kanig JL (1965) Increasing dissolution rates and gastrointestinal absorption of drugs via solid solutions and eutectic mixtures 1.Theoretical consideration and discussion of the literature. J Pharm Sci 54: 1145-1148.

3. Goldberg AH, Gibaldi M, Kanig JL (1966) Increasing dissolution rates and gastrointestinal absorption of drugs via solid solutions and eutectic mixtures II: experimental evaluation of eutectic mixture: urea-acetaminophen system. J Pharm Sci 55: 482-487.

4. Goldberg AH, Gibaldi M, Kanig JL, Mayersohn M (1966) Increasing dissolution rates and gastrointestinal absorption of drugs via solid solutions and eutectic mixtures.IV.chloramphenicol--urea system. J Pharm Sci 55: 581-583.

5. Hoerter D, Dressman JB (1997) Influence of physicochemical properties on dissolution of drugs in the gastrointestinal tract. Adv Drug Del Res 25: 3-14.

6. Hancock BC, Zografi G (1997) Characteristics and significance of the amorphous state in pharmaceutical system. J Pharm Sci 86: 1-12.

7. Loftsson T, Brewster ME (1996) Pharmaceutical applications of cyclodextrins.1.Drug solubilization and stabilization. J Pharm Sci 85: 10171025.

8. Astakhova AV, Demina NB (2004) Modern drug technologies: synthesis, characterization, and use of inclusion complexes between drugs and cyclodextrins (A Review). Pharm Chem J 38: 105-108.

9. Bell GD, Dowling RH, Whitney B, Sutor DJ (1975) The value of radiology in predicting gallstone type when selecting patients for medical treatment. Gut 16: $359-364$

10. Bouchier IAD (1980) The medical treatment of gallstones. Annu Res Med 31: 59-77.
11. Dowling RH (1983) Cholelithiasis: medical treatment. Clin Gastroenterol 12 : 125-178.

12. Bergmann VK, Epple-Gutsfeld M, Leiss O (1984) Differences in the effects of chenodeoxycholic acid and ursodeoxycholic acid on biliary lipid secretion and bile acid synthesis in patients with gallstones. Gastroenterology 87: 136-143.

13. Leuschner U, Leuschner M, Hubner K (1981) Gallstone dissolution with patients with chronic active hepatitis. Gastroenterology 80: 1208-1209.

14. Leuschner U, Kurtz W (1987) Treatment of primary biliary cirrhosis and cholestatic disorders with ursodeoxycholic acid. Lancet 2: 508.

15. Nagasamy Venkatesh D, Karthick S, Umesh M, Valliappan RM (2009) Studies on the preparation and characterisation of $\beta$-cyclodextrin aceclofenac Inclusion complexes. Malaysian J Pharm Sci 7: 153-168.

16. Dua Kamal, Sara UVS, Ramana MV (2007) Acidic Solubilizing Additives: Solubility Promoters for Aceclofenac Cyclodextrin Systems. Int J of Pharma Excip 4:101-105

17. Nisharani SR., Kulkarni. NS, Parth DM., AN Ranade. (2010) Improvement of water solubility and in vitro dissolution rate of aceclofenac by complexation with $\beta$-cyclodextrin and hydroxypropyl- $\beta$-cyclodextrin. Pharm Dev Tech 15: 64-70. http://informahealthcare.com/doi/abs/10.3109/10837450903002165

18. Scalia S, Pazzi P, Guaneri M (1989) Determination of bile acid in pharmaceutical dosage forms by Hplc. AnalLett 22: 915-927

19. Dahiya S, Pathak K (2006) Physicochemical characterization and dissolution enhancement of aceclofenac-hydroxypropyl $\beta$-cyclodextrin Binary Systems. PDA J Pharm Sci Technol 60: 378-388.

20. Dua K, Sara UV, Ramana MV, Pabreja K, Garg V, et al. (2007) Investigation of Enhancement of Solubility of Norfloxacin $\beta$-Cyclodextrin in presence of Acidic Solubilizing Additives. Current Drug Delivery 4: 21-25.

21. Patel HM, Suhagia BN, Shah SA, Rathod IS, Parmar VK (2007) Preparation and characterization of etoricoxib- $\beta$-cyclodextrin complexes prepared by the kneading method. Acta Pharm 57: 351-359.

22. Higuchi T, Connors A (1965) Phase-solubility techniques. In: Advances in Analytical Chemistry Instrumentation. 4: 117-211.

23. Chauhan B, Shimpi S, Paradkar A (2005) Preparation and characterization of etoricoxib solid dispersions using lipid carriers by spray drying technique. AAPS Pharm Sci Tech 6: E405-E412.

24. Papageorgiou GZ, Bikiaris D, Karavas E, Politis S, Docoslis A, et al. (2006) Effect of physical state and particle size distribution on dissolution enhancement of nimodipine/PEG solid dispersions prepared by melt mixing and solvent evaporation. AAPS J 8: E623-E631.

25. Bhargava S, Agrawal GP (2008) Preparation and Characterization of solid inclusion complex of cefpodoxime proxetil with beta-cyclodextrin. Curr Drug Deliv 5: 1-6.

26. Aigner Z, Hassan HB, Berkesi, O, Kata M, Eros I (2005). Thermoanalytical FTIR and X-ray studies of gemfibrozil-cyclodextrin complexes. J Therm Anal Calorim 81: 267-272.

27. Babu MMGV, Prasad CHSD, Ramana Murthy KV,Hima Sankar k,Kumar NK, et al. (2002) Development of new controlled release formulations of flurbiprofen: in vitro-in vivo correlation. Ind J Pharm Sci 64: 37-43.

28. Fernandes CM, Teresa VM, Veiga FJ (2002) Physicochemical characterization and in vitro dissolution behavior of nicardipine-cyclodextrin inclusion compounds. Eur J Pharm Sci 15: 79-88.

29. Costa P, Sousa Lobo JM (2001) Modeling and comparison of dissolution profiles. Eur J Pharm Sci 13: 123-133.

30. Sethia S, Squilante E (2004) Solid dispersions of carbamazepine in PVP-K30 by conventional solvent evaporation and super critical methods. Int J Pharm 272: $1-10$.

31. Martinez-ohariz MC, Rodriguez-Espinosa C, Martin C, Goni MM, Sanchez M, et al. (2002) Solid dispersions of diflunisal-PVP: Polymorphic and amorphous states of drug. Drug Dev Ind Pharm 28: 717-725.

32. Moffat AC, Osselton MD, Widdop B (2004) Clarke's analysis of drugs and 
Citation: Dua K, Pabreja K (2011) Investigation on Dissolution Pattern and Mathematical Modeling of Drug Release of UDCA by Complextaion with b-Cyclodextrin-Choline Dichloride Coprecipitate. J Liver 1:101. doi:10.4172/2167-0889.1000101

poisons in pharmaceuticals, body fluids and postmortem materials 2: 570-571.

33. Soni T, Chirag N, Teja G,Chotai NP (2008) Development of discriminating method for dissolution of aceclofenac marketed formulations. Dissolution Technol 5: 31-35.

34. Shivkumar HN (2008) Design and optimization of diclofenac sodium controlled release solid dispersions by response surface methodology. Ind J Pharm Sci 70: 22-30.
35. Mutalik S,Naha A,Usha AN, Ranjith AK,Manoj K, et al. (2007) Preparation, in vitro, pre-clinical and clinical evaluations of once daily sustained release tablets of aceclofenac. Arch Pharm Res 30: 222-234.

36. Rawat S, Jain SK (2007) Enhancement of intestinal absorption of few COX-2 inhibitors through interaction with $\beta$-cyclodextrin. Ind J Pharm Sci 69: 529-534. 